\title{
O INSTITUTO DE ESTUdos BRASILEIROS DA UNIVERSIDAdE DE COIMBRA: O LUGAR DO BRASIL
}

\author{
Élio Cantalício Serpa* \\ ecserpa@gmail.com \\ Heloisa Paulo** \\ heloisapaulo25@gmail.com
}

Resumo: A partir dos anos 40 do século XX, Portugal incrementou as relações com o Brasil. Da mesma forma, o Brasil durante o governo autoritário de Vargas procurar ampliar seu leque de relações e, nesse sentido, foram definidas políticas de aproximação que enfatizavam a grandeza histórica de Portugal e o Brasil se constituía em exemplo da grandiosidade portuguesa, agregando-se ao pressuposto da lusitanidade. O presente artigo tem como escopo discutir as relações Brasil/Portugal por intermédio da criação do Instituto de Estudos Brasileiros da Universidade de Coimbra.

PALAVRAS-CHAVE: Portugal, Brasil, Instituto de Estudos Brasileiros, Revista Brasília.

\section{A emergênCIA do IEB: As Comemorações Centenárias em Portugal}

Quando Portugal se preparou para as Comemorações Centenárias de 1940, Salazar fez um apelo ao governo do Brasil para que participasse nos eventos comemorativos, ajudando Portugal "a fazer as honras da casa", não sendo "apenas o nosso hóspede de honra, mas, como da família"(SALAZAR, 1943, p.45). A similaridade do regime então vigente no Brasil, igualmente denominado por "Estado Novo", os laços históricos construidos , a importância da colônia portuguesa radicada no território brasileiro, tornou a aproximação entre os dois regimes mais fácil. A

*Doutor em História/USP. Professor Associado Universdade Federal de Goiás.

** Doutora em História- Universidade de Coimbra. Pesquisadora CEIS20/Coimbra 
resposta de Vargas selou a comunhão de interesses ao afirmar que o Brasil vai comparecer ao evento "não como visitante mas, como membro da família que, embora politicamente dela separado, permanece fiel ao seu espírito e leal à sua amizade"1 .

O Estado brasileiro participou dos festejos do Duplo Centenário, enviando para Portugal não só uma comitiva de representantes oficiais, mas tomando a iniciativa de edificar o Pavilhão do Brasil e a parte brasileira no Pavilhão dos Portugueses no Mundo, por ocasião da Exposição Histórica do Mundo Português. O objetivo era "demonstrar a Portugal o culto do Brasil pela tradição comum" ${ }^{2}$. Desta comitiva fizeram parte alguns militares como o General de Divisão Francisco José Pinto, Chefe da Casa Militar do Presidente da República e presidente da representação brasileira, o coronel Tristão de Alencar Araripe, o Major Afonso de Carvalho e o Comandante Eugênio de Castro; representantes do Estado, como o Ministro Edmundo da Luz Pinto, diversos nomes da intelectualidade vinculada ao Estado Novo brasileiro, como Gustavo Barroso, responsável pela representação histórica do Pavilhão do Brasil, Osvaldo Orico, da Academia Brasileira de Letras, a quem coube a representação cultural, Olegário Mariano, poeta e escritor. Além do aval do Presidente Getúlio Vargas, os trabalhos da Comissão contaram com o apoio de dois nomes de relevo no cenário político brasileiro de então, Osvaldo Aranha, Ministro das Relações Exteriores, e o Embaixador do Brasil em Portugal, Dr. Artur Guimarães de Araújo Jorge.

O Pavilhão da ex-colónia, idealizado por Raul Lino e construído com a supervisão de um arquiteto brasileiro, Flávio Guimarães Barbosa, estava situado à entrada da Exposição, entre o Pavilhão da Fundação e o Pavilhão da Colonização, sobressaindo, pois, como um marco da História de Portugal, "uma das suas páginas mais belas e a sua mais extraordinária realização"(SALAZAR, 1943, p. 46) . Na sua primeira secção, composta de diversos expositores, foi dado realce às realizações do Estado Novo de Vargas, através da exposição de fotografias e de informações oficiais do governo daquele país. O café, que continua sendo a sua produção para a exportação mais conhecida, ganhou um espaço próprio sob a responsabilidade do Departamento Nacional do Café. A última secção foi dedicada à cultura, sendo o local de exposições de arte, sobretudo pintura e escultura, produzida por artistas brasileiros. A figura do General Carmona, então Presidente de Portugal, foi homenageada numa das salas, onde foram expostas as bandeiras históricas do Brasil.

O Departamento de Imprensa e Propaganda brasileiro tem a sua presença assinalada, logo à entrada do Pavilhão, sendo um dos responsáveis pelas muitas obras 
expostas na Exposição dos Livros, que reuniu publicações que versavam sobre as realizações e a ideologia do Estado Novo e sobre a cultura brasileira em geral. Ao público foi oferecido um grande número de publicações, rotogravuras, desenhos a bico de pena, folhetos e postais, além da exibição de curtas-metragens com o objetivo de propagandear o regime e as belezas naturais do país visitante.

Em 1941, a assinatura do Acordo Cultural Luso Brasileiro parece confirmar a aproximação cultural e ideológica entre os dois regimes. O Acordo foi firmado entre o Secretariado de Propaganda Nacional e o Departamento de Imprensa e Propaganda, a 4 de Setembro, no Palácio do Catete, sede do governo, no Rio de Janeiro, por António Ferro, diretor do órgão português, e por Lourival Fontes, diretor da instituição brasileira. Nos três artigos, que compõem o documento, são previstas, entre outras: a realização de um intercâmbio de publicações, a criação duma revista denominada Atlântico, mantida pelos dois organismos, com a colaboração de escritores e jornalistas portugueses e brasileiros, a troca de propaganda, de informações, de emissões de rádio, documentários cinematográficos, comemorações recíprocas e estudos de folclore lusobrasileiro. A finalidade é "tirar as relações entre Portugal e Brasil definitivamente do domínio das palavras"(FERRO, sd, p.227) .

No entanto, há muito tempo esta "finalidade" é perseguida por intelectuais próximos à realidade brasileira, sobretudo na Universidade de Coimbra, centro acolhedor de uma grande quantidade de alunos procedentes do Brasil desde o século XVIII ${ }^{3}$. Parte do acervo bibliográfico, rico para o entendimento da propaganda do Estado Novo do Brasil, nos anos 30 e 40, foi doado para a Sala Brasil da Faculdade de Letras da Universidade de Coimbra, pertencendo atualmente ao Instituto de Estudos Brasileiros. Na verdade, em 1937, o então reitor Dr. Mendes dos Remédios, promoveu a criação da "Sala Brasil", cujo objectivo inicial era abrigar livros e reunir todos aqueles que estivessem interessados em desenvolver estudos sobre temáticas brasileiras. É o primeiro passo para a criação do Instituto de Estudos Brasileiros, em Coimbra.

\section{A CRIAÇÃo do IEB E AS RELAÇões diPlomáticas entre Brasil E Portugal}

Em sessão solene, realizada na Faculdade de Letras da Universidade de Coimbra, em 03 de fevereiro de 1941, o Professor Doutor Providência da Costa propôs que a Sala do Brasil, inaugurada em 1937, passasse a ter o nome e as funções de 
Instituto de Estudos Brasileiros. Está registrado na revista Brasília que o referido instituto contou com o apoio de alguns docentes como: Joaquim de Carvalho, Carlos Simões Ventura, Amorim Girão e Rebelo Gonçalves. O último dirigiu o Instituto até 1952 quando, então, assumiu a direção o professor Álvaro J. da Costa Pimpão.

No ano seguinte, foi realizada a sessão solene de criação do IEB com a entrega do acervo bibliográfico do DIP (cinco mil volumes). Nesta ocasião houve pronunciamentos do Professor Rebelo Gonçalves, diretor da Sala do Brasil, do acadêmico Osvaldo Orico representando o embaixador brasileiro, Araújo Jorge, e, por fim, do Professor Providência da Costa. O brasileiro, Osvaldo Orico, destacou que o acervo é representativo da "própria inteligência brasileira" e representam "a mensagem preciosa do nosso culto, da nossa lealdade, da nossa veneração à gente portuguesa". Orico lembrou, ainda, que com a entrega da guarda do acervo o "povo brasileiro honrava nela o magistério por excelência, a dignidade do espírito sobre todas as virtudes efêmeras e todos os fastígios transitórios. Resgatava um "título sagrado" porque "à Universidade de Coimbra ficara o Brasil devendo por muito tempo a iluminação dos seus itinerários, o esclarecimento do seu entendimento, a formação das suas gerações, a modelação de suas almas e o estímulo da sua revelação" (BRASÍLIA, 1942, p 750).

O sentimentalismo visível nas palavras de Osvaldo Orico, no que concerne às negociações luso-brasileiras, expressa uma naturalização das relações que não corresponde ao conteúdo das reuniões de embaixadores do Brasil e de Portugal, de governantes de ambos os países no que tange à concretização de acordos, tratados e eventos propostos por Portugal e Brasil. "Culto", "lealdade" e "veneração" representam sentimentos expressados por intelectuais interessados em participar de eventos realizados ou na ex-metrópole ou na ex-colônia. Embora pudesse estar representando setores do governo brasileiro, suas palavras apontam para a transferência de opinião individual para o contexto nacional marcado pela heterogeneidade de posturas. Forma de expressão peculiar aos nacionalismos autoritários. Não são representativas do pensamento de uma imensa quantidade de intelectuais brasileiros que interpretavam o período colonial como forma de dominação e exploração, e condenavam o colonialismo português em África e Índia e também se aproximavam das relações com os Estados Unidos em diferentes campos.

Também não são representativas de intelectuais portugueses, como é o caso de Fidelino de Figueiredo que ao abordar a temática das relações entre Brasil e Portugal pontuou que 
os "aproximadores", com sua oratória sentimental, fazem obra de poesia estéril, quando não desservem a cordialidade entre as classes cultas dos dois países; considera que se batem por uma ilusão, obra dum daltonismo deformador, subsistência tardia de um imperialismo espiritual, quem sabe se novo avatar do sebastianismo delirante - que dá indícios de querer renascer. Sem falar nos empresários da aproximação, que só querem "faire l'Amérique"(FIGUEIREDO, 1954, p. 129).

A produção historiográfica brasileira tem registrado que na república o Brasil buscava itinerários próprios ao firmar acordos culturais e estabelecer contatos em diferentes esferas com outros países. Na década de 40 do século XX, o Brasil se ligava fortemente os Estados Unidos ${ }^{4}$. Lúcia Lippi de Oliveira enumera momentos importantes dessa aproximação com os EUA como: criação da agência Office for the Coordination of Inter American affairs (OCIAA) que incentivou a presença da cultura americana no Brasil, tendo como ápice a visita de Walt Disney, em 1941(OLIVEIRA, 2000, p 19).

Havia, ainda, a defesa da ideia de que os Estados Unidos seriam um modelo alternativo ao Brasil, largamente difundido nas obras de Alberto Torres, Oliveira Viana e Azevedo Amaral, conhecidos como arautos do pensamento autoritário no Brasil. Monteiro Lobato e Anísio Teixeira se fascinaram com o pragmatismo de John Dewey na construção de um modelo educacional mais democrático para o Brasil. E, por fim, percebe-se nos relatórios de Chancelaria que a partir dos anos 50 do século $\mathrm{XX}$ o governo brasileiro investiu de maneira significativa em centros e ou Institutos de Estudos Brasileiros ${ }^{5}$ voltados para a América do $\mathrm{Sul}^{6}$, embora isto não signifique abandono das relações com Portugal e, sim, alargamento das relações em direção a outros países.

A república brasileira, na sua constituição, não expressava uma filiação político/administrativa totalmente afinada com Portugal. José Sancheta Ramos Mendes registrou que entre 1894/1895 houve o rompimento diplomático entre Brasil e Portugal, motivada pelo envolvimento do Almirante Custódio José de Melo, líder da revolta da Armada com o Conde de Paço d’Árcos, representante do governo lusitano no Brasil. Tal fato lançou enormes suspeitas devido ao relacionamento amistoso entre o líder revoltoso e o representante do governo monárquico português. O estremecimento nas relações entre Brasil e Portugal se deu com a posse do vice-presidente, Floriano Peixoto, havendo a deflagração de uma segunda revolta da Armada sobre a tutela do Almirante Custódio de Melo. A forte repressão do governo de Floriano Peixoto fez com que muitos revoltosos brasileiros buscassem abrigo em embarcações portuguesas ancoradas na baia de Guanabara. Essa atitude foi lida pelo governo brasileiro como ataque à 
soberania nacional (MENDES, 2001, p.335-371). A emergência das idéias repúblicanas esteve sempre muito associada ao anticolonialismo, embora língua, literatura e história relembrassem a todo momento a herança portuguesa, mas era sempre objeto de contestação.

Em 1940 a Europa vivia uma experiência trágica e Portugal em festas, comemorava o duplo centenário, 1139 e 1640, formação e restauração da nacionalidade, respectivamente. Tal momento significou também uma nova fase do governo Salazar, marcada pela tentativa de superação da idéia de declínio, advinda de outros tempos. Nesta fase fazia uso da força avassaladora de produção de dispositivos que forjavam uma cultura histórica assentada no mito do passado glorioso. O Brasil ao participar como convidado especial das comemorações de 1940 desempenhou papel fundamental neste contexto, servindo de exemplo da capacidade administrativa de Portugal e da magnitude do colonialismo português.

Voltando aos discursos de inauguração do IEB, as palavras laudatórias de Orico, "aproximador" brasileiro, em relação ao significado da Universidade de Coimbra, cumprem um duplo papel. $\mathrm{O}$ elogio dirigido à universidade é também dirigido ao governo de Salazar que, como professor desta instituição, a elegeu como fornecedora de quadros para seu governo e também de sustentação ideológica ${ }^{7}$, e, portanto os louros dirigidos à Universidade são também simbolicamente canalizados ao regime salazarista. O poder do governo salazatista se encarna na universidade. Torgal ao fazer a leitura da universidade de Coimbra durante o Estado Novo registrou que:

a universidade aparece, numa concepção de unidade mítica, como afirmação das virtudes da civilização ocidental e cristã que o Estado Novo dizia representar, ao mesmo tempo que Salazar significava, no domínio da política, a projeção da Universidade, assim como o Cardeal Cerejeira correspondia ao seu prolongamento no domínio da fé (TORGAL, 1999, p. 121).

No ato mesmo de criação do Instituto de Estudos Brasileiros (1941) e da revista Brasília havia a presença de uma memória marcada por disjunções entre brasileiros e portugueses. Mario de Albuquerque, professor catedrático da universidade de Lisboa, foi convidado a escrever um artigo "doutrinário" para o primeiro volume da revista Brasília. O que não fez. Alegou que fora acometido por uma poderosa gripe, mas o IEB publicou na revista Brasília sua carta enviada por ocasião de fundação do Instituto de Estudos Brasileiros. Na carta, Mário de Albuquerque enfatizou que "para os portugueses é um dever, uma necessidade, conhecer integralmente o Brasil, na sua ação 
e no seu espírito, no seu passado e nas suas possibilidades atuais" (BRASILIA, 1942, p. 45).

De acordo com a escrita de Mário de Albuquerque, se Portugal colocou para si a responsabilidade de conhecer a ex-colônia também colocou para o Brasil a sua função, o seu lugar de seguidor: "encontrar no estudo das coisas portuguesas uma fonte de idéias e de energia espiritual - o conhecimento e o culto das origens foram sempre, para os povos, uma estímulo patriótico" (BRASÍLIA, 1942, p. 45) Na relação com o Brasil asseverou que "Portugal encontrou para seu momento de crise "certezas e esperanças consoladoras, verdadeiro antídoto para o pessimismo nacional". E continuou enfatizando que o estudo das coisas brasileiras possibilitou que os portugueses "auscultassem sua força plástica e modeladora" (BRASìlIA, 1942, p. 46). Na comparação com a Índia, “a epopéia brasileira é mais fecunda, mais duradoira"(BRASİLIA, 1942, p. 46). Assim o Brasil figura nesta narrativa como exemplaridade de como Portugal destacou-se pela tenacidade, capacidade de resistência, de sofrimento, sentido construtivo e plasticidade.

Mário de Albuquerque vale-se das palavras de seu pai que esteve exilado no Brasil, Rio de Janeiro, por 14 anos, qualificando esta experiência de "doce exílio". Seu pai constrói sua narrativa através de duas situações: a febre amarela e a ação dos jacobinos no Brasil. No que se refere à febre amarela destacou o papel que esta desempenhou na contenção da migração do norte da Europa para o Brasil. Alemães e italianos estabeleceram-se mais acentuadamente no sul do Brasil. Se o turbilhão das raças heterogêneas, diz o pai de Mário de Albuquerque, tivesse caído sobre o Brasil, o fundo lusitano não resistiria, teria sido dissolvido. A brasilidade que é desdobramento do lusitanismo, teria característica bem diversa, indefinida. A língua também teria se perdido pelos elementos perturbadores das línguas alheias se não fosse o apoio que o lusitanismo deu a brasilidade. No Brasil, as gentes heterogêneas serão dissolvidas e assimiladas. Pode lá cair a babel de todas as línguas, que todas serão impotentes para alterar a característica da língua portuguesa assumida no século XVI: língua comercial e dominadora. Profetizava que quando o Brasil atingir cem milhões de habitantes esta característica será acentuada (BRASÍLIA, 1942, p. 46).

$\mathrm{Na}$ leitura do pai de Mário de Albuquerque, o emigrante português no Brasil pela ação dos jacobinos reforçava o sentimento patriótico português. O jacobinismo é um mal que vem para o bem. A característica fundamental dos brasileiros é a sensibilidade, criando um meio de carinho, de conforto moral para os estrangeiros, 
principalmente para os portugueses, que não sentem a diferença entre as duas pátrias. A maioria dos brasileiros constitui-se em uma força centrípeta, tendente a absorver na nacionalidade os elementos portugueses, a minoria jacobina, constitui uma força centrífuga, tendente, pela hostilidade a repelir esses elementos. O emigrante português analfabeto, não tendo cultivo patriótico, apesar do seu sentimento português, perder-seia, triturado pela ação assimiladora da nacionalidade brasileira, se os jacobinos não lhes estimulassem a reação patriótica. Mário de Albuquerque deixa claro o sentido da ideia de conhecer o Brasil dizendo que: dar a conhecer, devotadamente, o Brasil a Portugal é praticar um ato da mais nobre política - política de pan-lusitanismo. (BRASÍLIA, 1942, p. 49).

Segundo Lúcia Maria Paschoal Guimarães, no governo provisório de Vargas (1934-1937), Gustavo Capanema, ministro da Educação e Saúde lançou o "Programa moderno e prático de propaganda cultural do Brasil no estrangeiro" sob a responsabilidade do Serviço de Cooperação Intelectual. Dentro desse programa diversas ações foram desencadeadas como: permuta de professores, técnicos, escritores, artistas e estudantes, revisão de livros de história e de geografia publicados em outros países; subvenção à edição de revistas estrangeiras que divulgasse matérias referentes a assuntos brasileiros; estímulo à criação da cadeira de literatura brasileira em universidades da Europa e dos Estados Unidos; organização de congressos científicos e outros eventos e também patrocínio à criação de 04 Institutos de Alta Cultura que deveriam estar sediados em Portugal, Itália, França e Alemanha (GUIMARÃES, 2009, p. 137).

O governo brasileiro institucionalizou políticas de inserção cultural do Brasil em outros países, abrindo-se para a Europa e Estados Unidos e, talvez, o último, aos olhos de Portugal, constituiu-se em fantasma que precisava ser observado e contido na sua expansão através da política do panlusitanismo que se projetava no interior de uma nova ordem mundial. Os pan-etnicismos das primeiras décadas do século XX giravam em torno dos nacionalismos étnicos, lingüísticos ou culturais e serviam, agora, de bases ideológicas para reordenar e legitimar novos blocos de alianças e acordos políticos, comerciais, econômicos, destronando a velha ordem dos impérios coloniais. À época falava-se em turkificação do Império Otomano, russificação das terras tzaristas, panamericanismo, pan-eslavismo e pangermanismo. (FLORES, 2001, p. 19).

Percebe-se que a criação do IEB (Instituto de Estudos Brasileiros) foi um esforço português para contenção dos efeitos dos discursos contrários ao colonialismo, 
ao seu papel de país moderno e civilizador e também responder a emergência de discursos que ensejavam à americanização. Como contrapartida Portugal fomentou uma série de práticas culturais dirigidas fundamentalmente para três campos de produção de saberes: a filologia mais tarde linguística, cuja preocupação maior era com a preservação da língua portuguesa, a história e a literatura. Nesse contexto, língua, história e literatura vão se constituir em um tripé de discussões acaloradas, produzindo vozes que enfatizavam a união através da realização de acordos culturais e também a disjunção visível nas políticas de normalização da língua e também nos encaminhamentos dados pela intelectualidade brasileira na leitura daquilo que era chamado de passado comum.

O IEB foi um dos lugares dos quais Portugal poderia "olhar o Brasil", incrementando políticas de defesa do passado comum. A difusão para o Brasil da tradição cultural da Universidade de Coimbra e seu papel de formação das elites brasileiras parece ser o leimotiv do IEB. Uma lembrança que os brasileiros não poderiam esquecer. É claro que propagar o papel civilizador da Universidade de Coimbra, ao longo de sua existência, coadunava-se com a cultura política salazarista de difusor do ideário colonialista assentado nos pressupostos da "política do espírito" e da constituição do Quinto Império. Assim, o futuro previsto (Quinto Império), elabora o sentido do presente e também do passado, dando sustentação para o fortalecimento da crença de que o futuro grandioso estava por vir. Horizonte a ser conquistado rapidamente, fortalecendo a imagem mítica do governante totalmente voltado para os interesses da nação.

A tônica discursiva do IEB são as glórias da Universidade de Coimbra como difusora de conhecimentos e lugar onde brasileiros se constituíram intelectualmente. Nesse sentido foi publicado pelo IEB um volume especial da revista Brasília arrolando brasileiros que tiveram sua formação concluída na Universidade de Coimbra. Neste instituto o Brasil também ocupava uma posição especial: a partir deste espaço o "filho dileto", como financiador do referido Instituto, dava visibilidade à sua produção intelectual, constituindo um ambiente favorável para que setores da intelectualidade brasileira se projetassem além de suas fronteiras.

Como já foi dito anteriormente a iniciativa de criação do IEB foi precedida da solicitação de brasileiros por ocasião da sessão solene de entrega de livros á Sala do Brasil. O acervo bibliográfico cedido pelo Brasil, compôs uma exposição que documentava o movimento científico e literário brasileiro - Exposição do Mundo 
Português - organizada para os festejos do duplo centenário, realizados em 1940. O que motivou a criação do Instituto de Estudos Brasileiros, segundo relato constante no primeiro volume da revista Brasília, foi a "necessidade de aumentar e dirigir melhor a ação cultural brasileira exercida entre nós” (BRAŚ́LIA, 1942, p. 749).

Na motivação para a criação do IEB há dois verbos que merecem atenção: “aumentar" e "dirigir". Havia nesse momento, por parte de Portugal a vontade política de mostrar para dentro e para fora o futuro que almejava articulado com o significado do seu passado dito glorioso, mostrando o seu papel civilizador. A criação do IEB está também relacionada com a celebração do Acordo Cultural de 1940. Por este Acordo, entre tantas ações conjuntas, estava a publicação de livros, revistas, congressos e também posições tomadas pelo Brasil no contexto das relações internacionais. $\mathrm{O}$ Acordo, assinado em 04 de setembro de 1941, era lido pelos portugueses como "um lugar propício para comunhão de idéias e de sentimentos, identidade de civilização e de idéias de justiça, identidade da base moral da vida de cada um dos dois povos" (BRASÍLIA, 1942, p. 541).

O Brasil, sob a égide do governo autoritário de Vargas, aproveitava esses momentos para divulgar suas ações no campo cultural e projetar o país. Dessa forma, o "aumentar" pode significar corresponder ao interesse de criar e aumentar mecanismos que assegurassem a presença do Brasil em Portugal. Porta de entrada para outros países europeus. Pode ter o sentido de que ex colônia, culturalmente, estivesse sempre visível em Portugal, para demonstrar no tempo presente a existência de unidade política e cultural, tão necessária, no presente e no futuro, aos interesses colonialistas portugueses em África. Para ambos os países, de forma diferenciada, significava criação de suporte para a validação da produção de práticas culturais e incremento das relações comerciais. Isto significava saber ou conhecer os rumos que Portugal e Brasil estavam tomando no contexto das divisões ideológicas e também do pan-americanismo.

O “aumentar" não se desvincula do "dirigir" que pode significar dar encaminhamentos adequados às demandas, mas também observar, avaliar e controlar o movimento intelectual brasileiro que dava sinais de disjunção através de leituras advindas da semana de arte moderna e também de interpretações historiográficas que colocavam em xeque a generosidade e a capacidade científica e criadora da antiga metrópole. Há uma vasta literatura que questiona o emprego da racionalidade técnica nos descobrimentos, redundando em discussões acaloradas sobre "casualidade ou intencionalidade" no descobrimento do Brasil. Além disso, no Brasil, muitos 
intelectuais abraçavam reflexões que colocavam em tensão a vinculação com Portugal e também condenavam o colonialismo português, principalmente a partir de 1945.

No Brasil, a intelectualidade investia em outras reflexões que extrapolaram a mera discussão das origens e o passado comum. A preocupação girava em torno da produção de obras que possibilitassem a "compreensão das nossas cousas e do nosso povo", como é o caso do trabalho de Nelson Werneck Sodré, intitulado O que se deve ler para conhecer o Brasil, seguido dos trabalhos Manual Bibliográfico de Estudos Brasileiros, sob a direção de Rubens Borba de Morais; Coleção Brasiliana, dirigida por Américo Jacobina Lacombe, quem lançou, em 1949, o livro Teoria da História do Brasil, de José Honório Rodrigues, direcionado à formação de historiadores e professores; prefácio à $5^{a}$ edição de Raízes do Brasil, feito por Antonio Candido de Mello e Souza e, finalmente, a publicação do artigo de Sérgio Buarque de Holanda, no jornal Correio da Manhã, em 1951, intitulado O pensamento histórico no Brasil nos últimos 50 anos. Estava em curso o pressuposto fundamental de que era preciso "conhecer o Brasil", o que significava um duplo movimento: compreender sua história e também sua produção historiográfica para então investi-la de um novo tratamento, operar com novas abordagens, juntar o pertinente para então olhar o passado com outros olhos (FRANZINI, 2009, p. 113-115), . Sérgio Buarque de Holanda publicou outros artigos que mexiam com o brio dos portugueses como reveladores e arautos da verdade, tal é o caso de Estudos luso-brasileiros, (COSTA, 2011, p.233) Portugueses da América, (COSTA, 2011, p.277) Historiografia portuguesa (COSTA, 2011, p.285) .

Ainda nos anos 50, a pauta da crise brasileira e sua superação fazia parte das preocupações de intelectuais ligados ao ISEB, criado em 1955, definindo como um dos motivos do atraso brasileiro os efeitos do colonialismo que precisavam ser superados e, para isso, era preciso "inventar nosso destino e construir uma cultura que fosse a expressão, a forma adequada de um novo pais" (VALE, 2006, p.). Em 1960, Sérgio Buarque de Holanda criticou o modo como os portugueses escreviam a história, qualificando-o de "zelo patriótico". Diz então que:

O mal desse zelo patriótico, em particular das acerbas primazias - Pierre Chaunu aludia, não há muito, ao "nacionalismo retrospectivo" verdadeiramente incomparável de inúmeros historiadores portugueses - , não está apenas em que ele tende a falsificar ingenuamente o passado, mas também em que provoca, num inevitável contragolpe, outras reivindicações nacionais que, por serem não raro tão pouco científicas quanto elas, podem refazer-se, ao cabo, mais eficazes. Não é assim de admirar que a obra dos navegadores e descobridores portugueses tenha dado origem a increpações injustas ou até absurdas (HOLANDA, 2011, p. 286). 
Já foi sobejamente discutido na historiografia que o desejo de Salazar de valorizar o passado colonial português voltava-se também para o enfrentamento da questão colonial. A aproximação com o Brasil representava uma estratégia de utilização do passado colonial, no claro intuito de demonstrar o laço fraterno que unia os dois povos, que outrora vivenciaram a situação metrópole/colônia, em uma mesma cultura: a luso-brasileira. Essa obsessão portuguesa pelo passado glorioso é tão forte que o subsecretário de Estado norteamericano, George Ball, trazendo à tona suas memórias referentes às discussões entre EUA e Portugal acerca da descolonização relatou ironicamente ao presidente Kennedy que "era um equívoco pensar que Portugal estava sob o controle de um ditador. Em vez disso ele era governado por um triunvirato composto por Vasco da Gama, pelo infante D. Henrique, o Navegador e por Salazar" (DÀVILA,2011, p.30) Finalmente, pretendia demonstrar, na ritualização da história, que a unidade luso-brasileira poderia ser tomada como referência para a redefinição dos laços entre Portugal e suas colônias.

O Acordo Cultural de 1940 buscava também manutenção de reciprocidades de ações. Assim, o Estado brasileiro recebeu afetuosamente os afagos do regime salazarista, aceitando participar da Exposição do mundo português, em 1940, na condição especial de país irmão, pois foi o Brasil o único país independente convidado. Contudo, Vargas não compareceu às festividades, apesar de insistentes convites. $\mathrm{O}$ empreendimento comemorativo reabria o debate acerca da presença dos portugueses na formação da identidade nacional. Discussão complexa que acompanhou a passagem do Império à república e constituiu campo de polêmicas infindáveis (FLORES, 2001, p.18). A relação entre Portugal e Brasil, durante a Era Vargas, também não era tão tranquila. Segundo Filipe Ribeiro de Meneses "o posicionamento diplomático de Getúlio Vargas durante a guerra foi motivo de grande frustração para Salazar: o que especialmente feriu a sensibilidade foi a cooperação crescente entre o Brasil e os Estados Unidos da América, bem mais substancial do que a existente entre o Brasil e Portugal" (MENESES, 2011, p. 26) (MENESES, 2011, p. 26). Mas o Brasil já americanizava em outros escaninhos que não o das relações diplomáticas ou entre governantes ${ }^{8}$.

\section{O PESO DA PRESENÇA BRASILEIRA NO IEB: PORTUGAl E A ANTIGa COLÔNiA.}

A criação do IEB atende fundamentalmente às demandas de brasileiros afinados com o papel e o ideário universitário da época Salazarista e também daqueles que 
investiam no peso da presença da tradição portuguesa no Brasil, diante da heterogeneidade preocupante que o Brasil apresentava em termos étnicos e culturais. Some-se a isso a presença do regionalismo que na tessitura de discursos de origens e de teses assimilacionistas esqueciam ou subalternizavam o papel de Portugal e, pareciam, com isso, comprometer o tradicional discurso da unidade nacional e da origem comum portuguesa.

O Instituto de Estudos Brasileiros tinha um programa a ser seguido do qual constava: a) publicação da revista Brasília como seu órgão de informação e de cultura, b) enriquecimento do acervo bibliográfico ${ }^{9}$,c) promoção conferências de professores, eruditos, homens de ciência e de letras do Brasil e de Portugal, sobre os mais variados aspectos da vida, da história, da literatura e da cultura brasileira d) publicações de varia natureza e amplitude, e) desenvolvimento do intercâmbio cultural entre Brasil e Portugal f) correspondência e permuta de publicações com as universidades e institutos brasileiros, g) organização de um serviço de informações sobre a vida cultural de Portugal e do Brasil h) apoio à iniciativas que visem fortalecer as relações culturais entre os dois países (BRASÍLIA, 1942, p.750) .

Considerando seu programa de atuação o IEB, até 1968, pautou sua existência em duas direções muito precisas. Primeiramente, oferecia aos brasileiros, considerados ilustres que visitavam Portugal, espaço para proferirem conferências como é o caso de Afrânio Peixoto, Gilberto Freire, Pedro Calmon, Embaixador Araújo Jorge e também para intelectuais portugueses que abordavam as relações entre Brasil Portugal, a exemplo de Julio Cayola entre outros. O IEB também participava da organização de solenidades de concessão do título doutor honoris causa pelo Universidade de Coimbra concedido, por exemplo, a Afrânio Peixoto, ao Reitor da Universidade de São Paulo, Pedro Calmon, Gilberto Freire. Organizava congressos relacionados com a história e com a língua. Era também responsável, através de seu diretor pela captura de intelectuais dispostos a fazer resenha de livros brasileiros, publicação de artigos relacionados com o Brasil e também publicação de documentos considerados relevantes para a história do Brasil. Essas atividades constituíam-se em ocasiões propícias para a manifestação de apoio às ações que davam visibilidade às relações entre Brasil e Portugal. O IEB foi um lugar também de visibilidade da projeção cultural Brasil projetada pelo Estado brasileiro, através do Ministério das Relações Exteriores.

Para Portugal o IEB constituiu-se em um lugar de tessitura de narrativas e outras práticas no afã de articular passado, presente e futuro com a perspectiva de construção 
de um futuro, enredando a ex- colônia com vistas à concretização do V Império. Em cumprimento ao enunciado de que "Portugal e Brasil sentem-se tão intimamente iluminados pela mesma consciência histórica, que, onde quer que do Brasil se fale, a Portugal se exalta", a revista Brasília, na sessão intitulada comentários arrola uma série de eventos com o objetivo de comprovar o enunciado "iluminados pela mesma consciência histórica".

Está registrado na revista que houve eleição de sócios correspondentes pela Sociedade de Estudos Filológicos de São Paulo. Foram eleitos: Antenor Nascentes, Padre Augusto Magne e Álvaro Ferdinand de Sousa da Silveira. Foram enviados ao IEB mapas cartográficos do Brasil, demanda solicitada quando da passagem por Portugal, em 1939, da caravana Universitária Paulista; houve realização de Curso de Férias reservando um dia de estudo sobre a cultura brasileira. A academia de Ciências de Lisboa concedeu distinção a 07 brasileiros: Olegário Mariano, Gustavo Barroso, Osvaldo Orico, Cláudio de Sousa, Celso Vieira, Levi Carneiro e ao Comandante Eugênio de Castro. Nos mesmos princípios de irmandade cultural, a Academia Brasileira de Letras instituiu dez cadeiras e as preencheu com membros portugueses. Tomaram assento três portugueses: Joaquim Leitão, Egas Moniz, Fidelino de Figueiredo, Carlos Malheiros Dias e José Maria Rodrigues. Nas comemorações do centenário de Antero de Quental o Brasil comungou com Portugal este evento. O prefeito do Rio de Janeiro, Henrique Dodsworth, assinou decreto que concedeu o nome de Antero de Quental a uma das principais ruas da capital do Brasil e a Academia Brasileira de Letras associou-se a este evento nomeando como representantes nas comemorações anterianas: Pedro Calmom, Ribeiro Couto e Osvaldo Orico. No fervor das exigências do Acordo Cultural Luso-brasileiro a revista noticia a criação da cadeira de Estudos Brasileiros. É registrado um grande problema: quem terá competência para assumir esta cadeira? Aparece como sugestão o nome do Comandante Eugênio de Castro (NUNES, 1943, p.727-729).

A apregoada "consciência comum" entre Portugal e Brasil é louvada com a realização de várias conferências de brasileiros em Portugal e também pela Câmara Portuguesa de Comércio, em São Paulo. Criação do curso de Civilização Portuguesa na Faculdade Nacional de Filosofia da Universidade do Brasil, publicação do Jornal do Atlântico, editado juntamente com a revista Atlântico, pelo Secretariado da Propaganda Nacional. Numa demonstração de afinidades entre governos louvou-se a indicação do Visconde de Canaxide para compor a delegação do Secretariado de Propaganda 
Nacional junto ao Departamento de Imprensa e Propaganda e também, com idêntica finalidade o DIP nomeou seu representante junto do SPN, José Cesário Alvim, escritor e jornalista. Houve a reorganização do Grupo de Estudos Brasileiros, na universidade do Porto ficando sob a responsabilidade de Pinto do Couto, professor da Escola de Belas Artes. A revista noticiou a substituição de Lourival Fontes no Departamento de Imprensa e Propaganda e a conseqüente nomeação do Major Antônio Coelho dos Reis para substituí-lo. Na Academia Brasileira de Letras houve a nomeação de 40 "devotos das letras" e muitos são "servidores da Ciência" e nesse conjunto foi registrado, quase no final da nota, a indicação do presidente Getúlio Vargas que ocupou a cadeira de Alcântara Machado e termina dando a conhecer o concurso, literário, artístico histórico e científico com apoio do Secretariado de Propaganda Nacional (PT) e do Departamento de Imprensa e Propaganda (BR), tendo como invocação o cronista Pero Vaz de Caminha. $\mathrm{O}$ vitorioso receberá prêmio em dinheiro e visita ao Brasil ou a Portugal pelo vencedor (NUNES, 1943, p 729-731).

Percebe-se que o IEB, durante a sua existência foi financiado pelo governo brasileiro através de destinação de recursos oferecidos pela Divisão de Cooperação Intelectual do Ministério das Relações Exteriores do Brasil. A partir de 1950 tal órgão passou a ser denominado Divisão Cultural do Ministério das Relações Exteriores do Brasil. A cedência de espaço físico ao IEB constituiu-se como maior ou única contribuição de Portugal, ou se quisermos da Universidade de Coimbra.

Nos relatos publicados na revista Brasília a situação do IEB, em termos de funcionamento, deixava a desejar. Até o inicio do ano letivo de 1951/1952 o IEB esteve sob a direção do Professor Doutor Rebelo Gonçalves, que, em 1942 fundou e assumiu a editoração da revista Brasília. A partir de 1952 a revista e o IEB passaram a ser coordenados pelo professor doutor Álvaro J. da Costa Pimpão, professor catedrático da Faculdade de Letras de Coimbra. Costa Pimpão logo que assumiu a direção do IEB entrou em contato com o embaixador do Brasil, senhor Doutor Samuel de Souza-Leão Gracie, sendo recebido pelo Encarregado dos Negócios, senhor doutor Garcia de Sousa . No mesmo ano, o Encarregado dos Negócios colocou à disposição do IEB, generoso donativo, correspondente à subvenção relativa a 1952, que o governo Brasileiro concedeu ao IEB. Segundo Costa Pimpão, a posse dos recursos permitiu a abertura do IEB, da biblioteca e a manutenção de um catalogador privativo.

O primeiro volume da revista Brasília veio à lume em 1942. Nela está explícito que concorreram para a publicação da revista o Instituto para Alta Cultura e o 
Secretariado da Propaganda Nacional e, inicia o volume com saudação do Cardeal Patriarca Manuel Gonçalves Cerejeira, Mário Figueiredo, Ministro da Educação Nacional e J. Providência da Costa, diretor da Faculdade de Letras da Universidade de Coimbra. O que se depreende é que o IEB e a revista são criações de Portugal para o Brasil, mas quem os mantém, em termos de aportes financeiros, é o Brasil. O volume II da revista Brasília destaca que concordaram para a publicação deste volume o Secretariado de Propaganda Nacional e o Instituto para Alta Cultura e a Divisão de Cooperação Intelectual do Ministério das Relações Exteriores do Brasil. A partir do segundo volume, o Brasil passou a ser o financiador da revista Brasília. Em todos os outros volumes há menção à Divisão Cultural do Ministério das Relações Exteriores do Brasil como único órgão que "concorreu para a publicação" e a revista é propriedade do IEB.

Concluindo, o Brasil financiava o IEB e a publicação da revista Brasília, mas não participava como mentor, contribuindo na editoração da revista. Não há também sinais que demonstrem que a intelectualidade brasileira tenha participado na elaboração conjunta de políticas para o IEB. Para o Brasil o IEB funcionava como um lugar de visibilidade de alguns intelectuais brasileiros que ao irem a Portugal pronunciavam conferências em Coimbra e também como lugar de recepção para homens que recebiam o título de "doutor honoris causa" concedido pela Universidade de Coimbra. Para a exmetrópole o IEB servia para a expansão do discurso do colonizador. Não há como negar essa questão. Colado a isto estava a preocupação com constituição de grupos de intelectuais afinados com ideário autoritário de Salazar que difundiriam para dentro e para fora suportes ideológicos calcados na ideia de uma passado glorioso, com vistas a assegurar no presente, a aceitação das políticas autoritárias de Salazar, cujo futuro pós 45, alicerçado na ideia de V Império, encontrava-se ameaçado.

\section{BRAZILIAN STUDIES INSTITUTE OF THE UNIVERSITY OF COIMBRA: THE PLACE OF BRASIL}

ABSTRACT: From the 1940's, Portugal increased relations with Brazil. Likewise, Brazil during Varga's authoritarian government sought to broaden its range of relationships and, in this sense, aproach policies that emphasized the historical greatness of Portugal were defined and Brazil constituted itself in example of the portuguese greatness, agreggating the assumption of lusitanity. This article aims to discuss the Brazil/Portugal 
relations through the formation of the Brazilian Studies Institute of the University of Coimbra.

KEYWORDS: Portugal; Brazil; Brazilian Studies Insitute; Brasília Magazine.

\section{NOTAS}

${ }^{1}$ Resposta de Getúlio Vargas ao convite de Portugal, citada na entrada do Pavilhão do Brasil.

2 Comitiva Brasileira dos Centenários. Pavilhão do Brasil nas Comemorações Centenárias. Lisboa, 1941, s.p..

${ }^{3}$ Ver, entre outros, DIAS, Pedro; TORGAL, Luís Reis - A Universidade de Coimbra, Coimbra, Imprensa da Universidade, 1978; GOMES, Joaquim Ferreira - Estudos para a História da Universidade de Coimbra. Coimbra, Livraria Minerva, 1991; RODRIGUES, Manuel Augusto - A Universidade de Coimbra. Marcos da sua História, Coimbra, Arquivo da Universidade, 1991..

${ }^{4}$ Sobre esta questão ver: VIANNA, Luiz, Werneck. A revolução passiva: iberismo $e$ americanismo no Brasil, 2a edição, Rio de Janeiro, Editora Revan, 2004. TOTA, Antonio Pedro. O imperialismo sedutor. A americanização no Brasil na época da segunda guerra, São Paulo, Companhia das Letras, 2000.

5 Segundo relatório de Chancelaria "esses dois tipos de instituições afetos à Divisão Cultural e Intelectual servem para promover, sobretudo nos países latino-americanos, o ensino intensivo de língua portuguesa e para divulgar, em caráter sistemático, a civilização barsileira em seus diversos aspectos. (Relatório de Chancelaria. Biblioteca do Ministério das Relações Exteriores, Brasília, 1965, p 247-248.

${ }^{6}$ O relatório de Chancelaria de 1965 aponta para 11 Centros de Estudos Brasileiros em funcionamento na América do Sul e também existiam Institutos de Cultura Brasileira no Uruguai, nos Estados Unidos da América e Instituto Cultural Uruguaio Brasileiro em Montevidéu e Instituto Brasil-Estados Unidos em Washington, (Relatório de Chancelaria. Biblioteca do Ministério das Relações Exteriores, Brasília, 1965, 249).

${ }^{7}$ Sobre esta questão ver: TORGAL, Luís Reis. A universidade e o Estado Novo, Coimbra, Minerva, 1999.

${ }^{8}$ Nesse sentido ver: TOTTA Antonio Pedro. O imperialismo sedutor. A americanização 
do Brasil na época da segunda guerra, São Paulo, Companhia das Letras, 2000. BANDEIRA Luiz Alberto Muniz . Presença dos Estados Unidos no Brasil, Rio de Janeiro, Civilização Brasileira, 2007. OLIVEIRA, Lucia Lippi. Representações da identidade nacional no Brasil e nos EUA, Belo Horizonte, Editora da UFMG, 2000. VIANNA, Luiz WERNECK. A revolução passiva. Iberismo e Americanismo no Brasil, Rio de Janeiro, Revan, 2004.

${ }^{9}$ Em cumprimento ao programa, o Instituto publicou um Catálogo de Manuscritos da Biblioteca Geral da Universidade de Coimbra relativos ao Brasil. Catálogo organizado por Dr. Francisco Morais. É formado por Extratos do Catálogo da Universidade de Coimbra".Além deste catálogo, segundo o relator, está sendo preparada a publicação de um Minucioso Inventário dos Manuscritos da Biblioteca da Ajuda Relativos à América do Sul, organizado pelo Sr. Carlos Alberto Ferreira

\section{REFERÊNCIAS}

SALAZAR, António de Oliveira. Discursos e Notas Políticas. 1938/1943. vol. III. Coimbra, Coimbra Editora Lda, 1943, p. 45

FERRO, António. in: Anais da Revolução Nacional. 1939/1945. vol. V. Barcelos, Companhia Editora do Minho, s.d., p.227

Relatório de Chancelaria. Biblioteca do Ministério das Relações Exteriores, Brasília, 1965 ,

Revista Brasilia. Instituto de Estudos Brasileiros, 1942,

FIGUEIREDO, Fidelino. Estudos de História Americana. São Paulo: EditoraProprietária Companhia. Melhoramentos de São Paulo, 1954, p. 129.

OLIVEIRA, Lúcia Lippi. Americanos. Representações da identidade nacional no Brasil e nos EUA. Belo Horizonte, Editora UFMG, 2000

MENDES, José Sancheta Ramos,. "Somos da América e queremos ser americanos": relações Brasil-Portugal e o antilusitanismo na fundação da república. Revista IHGB.a. 172(452):335-371, jul/set.2011.

TORGAL, Luís Reis. A universidade e o Estado Novo, Coimbra, Minerva, 1999.

Revista Brasília. Instituto de Estudos Brasileiros, vol. I, 1942. 
GUIMARÃES, Lúcia Maria Paschoal Org. Afinidades Atlânticas: impasses, quimeras e confluencias nas relações luso-brasileiras, Rio de Janeiro, FAPERJ, 2009.

FLORES, Maria Bernardete Ramos, SERPA, Elio Cantalicio e PAULO, Heloisa. $O$ beijo através do Atlântico: o lugar no Brasil no panlusitanismo, Chapecó, Argos, 2001.

FRANZINI, Fábio et al. Memória e história da historiografia no Brasil: a invenção de uma moderna tradição, anos 1940-1960, In: SOIHET, Raquel et al., Mitos, projetos e práticas políticas: memória e historiografia (Rio de Janeiro: Civilização Brasileira, 2009.

COSTA, Marcos. Org. Sérgio Buarque de Holanda. Escritos coligidos livro II- 19501979. São Paulo: Editora Fundação Perseu Abramo-Editora UNESP,.2011.

HOLANDA, S. B. Historiografia portuguesa. In: COSTA, Marcos. Org. Sérgio Buarque de Holanda. Escritos coligidos livro II- 1950-1979. São Paulo: Editora Fundação Perseu Abramo-Editora UNESP,2011

VALE, Antonio Marques do. O ISEB e os intelectuais e a diferença. Um diálogo teimoso na educação. São Paulo: UNESP, 2006.

Jerry DÁVILA. Hotel Trópico. O Brasil e o desafio da descolonização africana 19501980, São Paulo, Paz e Terra, 2011.

Filipe Ribeiro de MENESES. Salazar: biografia definitiva,Trad, Teresa Casal,São Paulo, Leya, 2011.

NUNES, João de Castro . Comentários.Coimbra. Revista Brasília, 1943

TOTTA Antonio Pedro. O imperialismo sedutor. A americanização do Brasil na época da segunda guerra, São Paulo, Companhia das Letras, 2000.

BANDEIRA Luiz Alberto Muniz . Presença dos Estados Unidos no Brasil, Rio de Janeiro, Civilização Brasileira, 2007.

OLIVEIRA, Lucia Lippi. Representações da identidade nacional no Brasil e nos EUA, Belo Horizonte, Editora da UFMG, 2000.

VIANNA, Luiz WERNECK. A revolução passiva. Iberismo e Americanismo no Brasil, Rio de Janeiro, Revan, 2004. 
DIAS, Pedro; TORGAL, Luís Reis - A Universidade de Coimbra, Coimbra, Imprensa da Universidade, 1978.

GOMES, Joaquim Ferreira - Estudos para a História da Universidade de Coimbra. Coimbra, Livraria Minerva, 1991.

RODRIGUES, Manuel Augusto - A Universidade de Coimbra. Marcos da sua História, Coimbra, Arquivo da Universidade, 1991. 